Pediat. Res. 2: 131-144 (1968)

Amino acids nutrition dietary protein plasma

infants aminogram

\title{
The Plasma Aminogram. I. Influence of the Level of Protein Intake and a Comparison of Whole Protein and Amino Acid Diets
}

\author{
Selma E. Snyderman ${ }^{[21]}$, L.E.Holt, Jr. ${ }^{[20]}$, Patricia M. Norton, Ellen Roitman and \\ S.V.Phansalkar \\ Department of Pediatrics, New York University School of Medicine, New York, New York, USA
}

\begin{abstract}
Extract
The changes in plasma aminogram prcduced by variations in level of protein intake provided either as whole protein or a mixture of amino acids were studied. Controls were 29 normal infants, one to three months of age, fed a standard evaporated milk formula providing 3 to $3.5 \mathrm{~g} / \mathrm{kg} /$ day of protein (fig. 1 and table II). Results obtained with the lowest protein intake $(1.1 \mathrm{~g} / \mathrm{kg} / \mathrm{day})$ are illustrated in figure 2 and presented in table III. Alterations in the plasma aminogram are noted as early as two days after the reduction in intake and become more pronounced as the feeding is prolonged. The most striking changes are depression of the branched chain amino acids (leucine, isoleucine and valine) and of lysine and tyrosine. Glycine and serine are elevated with glycine showing the greater elevation. Less striking changes are decreased concentrations of threonine, phenylalanine, ornithine, butyrine, cystine and proline.

The aminograms obtained with feedings of 1.3 and $1.5 \mathrm{~g} / \mathrm{kg} /$ day are very similar to those obtained with the more extreme degree of protein reduction (fig. 3 and table IV). The aminogram after feeding $1.7 \mathrm{~g} / \mathrm{kg} /$ day remains within the range of average \pm 1 standard deviation except for the elevation of glycine.

A high intake of milk protein, $9 \mathrm{~g} / \mathrm{kg} /$ day, results in an increase in the levels of a majority of the amino acids (fig. 5 and table V). The sole exception is glycine, which tends to be low. Marked increases occur in the branched chain amino acids, valine being the most affected; there is also a large increase in the level of proline. The greatest elevations occur in the levels of methionine, which also show the most marked individual variation, elevations ranging from 2 to 35 times normal average value. An apparent tendency of the methionine level to return towards normal with prolonged feeding of the high protein diet is evident on the graph. The significance of this finding must be questioned, however, since the subjects who were maintained the longest on this diet were those who originally did not have the very high levels of methionine.

There are some differences in the aminogram when infants are fed the equivalent of $3.5 \mathrm{~g} / \mathrm{kg} / \mathrm{day}$ in the form of amino acids instead of intact protein (fig. 6 and table VI). On the amino acid diets, lower average plasma values are seen for the branched chain amino acids, alanine, proline, asparagine and citrulline; higher values are observed for threonine and serine. The markedly elevated levels of plasma amino acid observed after feeding $9 \mathrm{~g} / \mathrm{kg} /$ day of whole protein are not seen after feeding the equivalent amount of nitrogen as an amino acid mixture (fig. 7 and table VII). There is elevation only of valine and serine. When individual subjects were shifted from the high protein to the high amino acid diet, the pattern shifted within 24 hours.
\end{abstract}




\section{Speculation}

A more precise and sensitive indicator of the state of protein nutrition is needed. While the level of the plasma amino acids changes rapidly with alterations in protein intake, much more work is necessary before it can be used to evaluate protein adequacy.

\section{Introduction}

Improvements in analytical techniques, notably the development of column chromatography initiated by Moore and STein [8], have made it possible to measure the individual free amino acids of the plasma with relative ease. It has seemed desirable to explore the value of the aminogram as a criterion of protein adequacy. We have, therefore, undertaken to study the changes in the plasma aminogram produced by variations in level of protein intake when provided as either whole protein or a mixture of amino acids. These will be described in the present study. In separate studies we shall describe our observations on the influence of protein quality - the effects of deficits and surfeits of particular amino acids on the plasma aminogram.

\section{Material and Methods}

Subjects. The subjects of the study were 15 normal infants one to six months old at onset of the study; seven had been born prematurely but had had an uneventful course in the premature unit and weighed over $3.0 \mathrm{~kg}$ when included in the study. Weights and ages are listed in table I. They were hospitalized for social

Table I. Ages and weights of babies studied

\begin{tabular}{llll}
\hline Baby & $\begin{array}{l}\text { Birth weight } \\
(\mathrm{kg})\end{array}$ & $\begin{array}{l}\text { Age-onset } \\
\text { of study } \\
\text { (months) }\end{array}$ & $\begin{array}{l}\text { Weight-onset } \\
\text { of study }(\mathrm{kg})\end{array}$ \\
\hline $\mathrm{De}$ & 2.18 & 1 & 3.0 \\
$\mathrm{Ri}$ & 1.75 & 2 & 3.5 \\
$\mathrm{St}$ & 1.75 & 3 & 3.58 \\
$\mathrm{Co}$ & 1.46 & 3 & 4.1 \\
$\mathrm{Mc}$ & 1.77 & 3 & 3.7 \\
$\mathrm{Me}$ & 1.85 & $31 / 2$ & 3.7 \\
$\mathrm{McR}$ & 1.51 & $51 / 2$ & 4.72 \\
$\mathrm{Be}$ & 3.32 & 1 & 4.1 \\
$\mathrm{Ec}$ & 2.7 & $11 / 2$ & 3.65 \\
$\mathrm{Ed}$ & 3.4 & $11 / 2$ & 4.45 \\
$\mathrm{Ko}$ & 3.29 & $11 / 2$ & 4.18 \\
$\mathrm{Riv}$ & 2.92 & 3 & 4.75 \\
$\mathrm{Al}$ & 3.17 & 5 & 8.1 \\
Ja & 2.58 & 5 & 5.25 \\
Jo & 3.7 & 6 & 7.5 \\
\hline
\end{tabular}

reasons and were kept on a metabolic ward and cared for by special nurses. All studies were done with the consent of parents or guardians.

Feedings. These were prepared from cow's milk; the protein intake of the subjects varied from 1.1 to 9.0 $\mathrm{g} / \mathrm{kg} /$ day. These variations were produced by diluting the milk and by supplementing it with different quantities of demineralized casein; they were made isocaloric by the further addition of carbohydrate in the form of dextrimaltose ${ }^{1}$ and fat as corn oil ${ }^{2}$. The formulas were fed at 110 calories per kilogram; their composition is shown in tabular form.

\begin{tabular}{lllllll}
\hline $\begin{array}{l}\text { Protein intake } \\
(\mathrm{g} / \mathrm{kg} / \text { day) }\end{array}$ & 1.1 & 1.3 & 1.5 & 1.7 & 9 & $\begin{array}{l}\text { Goup } \\
\text { group }\end{array}$ \\
\hline $\begin{array}{l}\text { Protein } \\
\begin{array}{l}\% \text { of calories) } \\
\text { Fat }\end{array}\end{array}$ & 4 & 4.7 & 5.4 & 6 & 32 & 12 \\
$\begin{array}{l}\text { (\% of calories) } 40 \\
\begin{array}{l}\text { Carbohydrate } \\
(\% \text { of calories) } 56\end{array}\end{array}$ & 50 & 39 & 39 & 24 & 36 \\
\hline
\end{tabular}

The amino acid diets were completely synthetic diets, the protein moiety of which is a mixture of 18 $L$-amino acids. They are complete diets containing carbohydrate, fat, vitamins and minerals and have been extensively used by the authors in studies of the amino acid requirements of infants. Details are given in reference 11 . These diets were fed at two levels of nitrogen intake corresponding to 3.5 and $9 \mathrm{~g}$ protein $/ \mathrm{kg} /$ day.

Control observations. These were made on 29 infants, fed a formula of evaporated milk and cane sugar providing 3 to $3.5 \mathrm{~g}$ protein $/ \mathrm{kg} / \mathrm{day}$. Within this range they were fed ad libitum. They were one to three months of age when blood samples were drawn. Five of these $29 \mathrm{ob}-$ servations were made in infants who later became subjects in the study.

Clinical performance. The infants remained healthy and gained satisfactorily in weight except during several of the periods while they were receiving the lowest pro-

1 Dextrimaltose, contributed by Mead Johnson and Co. 2 Mazola, contributed by Corn Oil Products Co. 
The plasma aminogram. I. Influence of the level of protein intake and a comparison...

tein intake, at which time there was some reduction in the rate of weight gain. Occasionally an intercurrent infection occurred in one or another subject; observations made at such times are not included.

Laboratory methods. The free amino acids were determined on heparinized plasma; blood samples were drawn four to five hours after a feeding and after the diet had been given for various periods of time. Details are given on the germane figures 1 through 7. Plasma samples were precipitated immediately with picric acid and prepared for analysis by the method of STEIN and MOORE [14]. All amino acid analyses were performed on a single stage Phoenix automatic amino acid analyzer using the procedure of PIEz and Morris [9]. Values for glutamic acid and glutamine are not reported because of the inconstant degree of conversion of glutamine to glutamic acid and because the prolonged maintenance of samples at relatively high temperature $\left(65^{\circ}\right)$ and low $\mathrm{pH}$ on this system permit the cyclization of glutamic acid with formation of pyrolidine carboxylic acid and ammonia. It has been possible to obtain a separate peak for asparagine in our laboratory (this is usually combined with glutamine), and hence valid figures for this amino acid are being reported. Observations on tryptophan are not included, since an accurate chemical procedure for its estimation was not available to us at the time most of these studies were carried out.

\section{Results}

Effects of Varying Levels of Protein Intake

These are depicted graphically in figures 1 to 5 . Figure 1 is the aminogram of 29 normal control infants, one to three months of age fed a standard evaporated milk formula providing 3 to $3.5 \mathrm{~g} / \mathrm{kg} / \mathrm{day}$ of protein. The average and one standard deviation above and below the average are illustrated. The data are listed in table II.

Results obtained with the lowest protein diet (1.1 $\mathrm{g} / \mathrm{kg} /$ day) are illustrated in figure 2 and presented in table III. Alterations in the plasma aminogram were noted as early as two days after the reduction in intake (no blood samples were drawn sooner), and the same alterations became more pronounced as the feeding time was prolonged. The most striking changes were

Fig. 2. The plasma aminogram after feeding $1.1 \mathrm{~g}$ protein $/ \mathrm{kg} /$ day for the lengths of time indicated on the figure. The figures in the parentheses are the number of subjects. They are plotted against the normal curve of figure 1 .

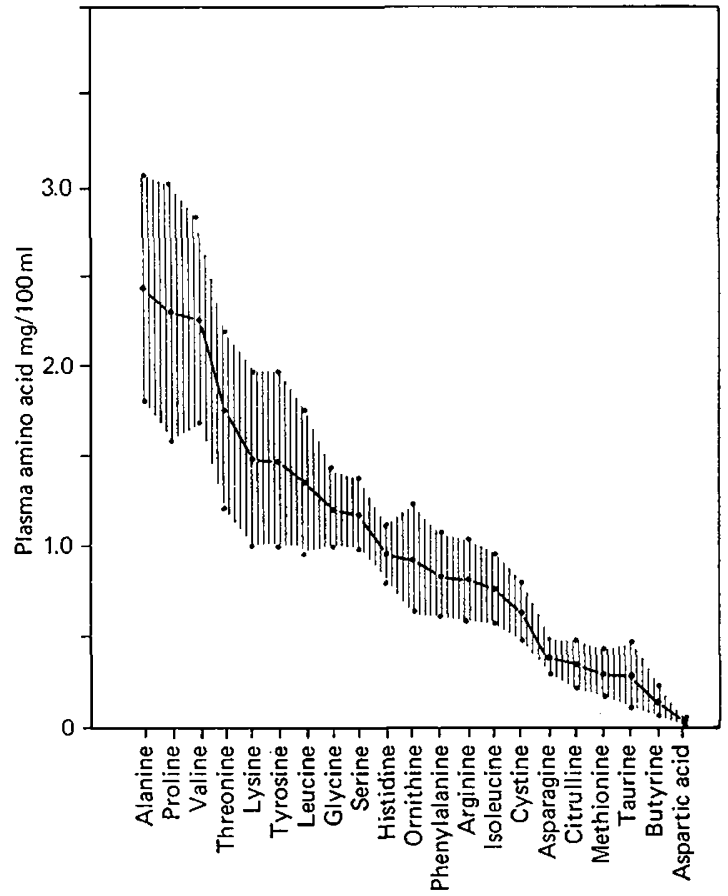

Fig. 1. The plasma aminogram of 29 normal infants fed a standard evaporated milk formula providing 3 to $3.5 \mathrm{~g}$ protein $/ \mathrm{kg} /$ day. The heavy line is the average and the shaded area represents one standard deviation above and below the average.

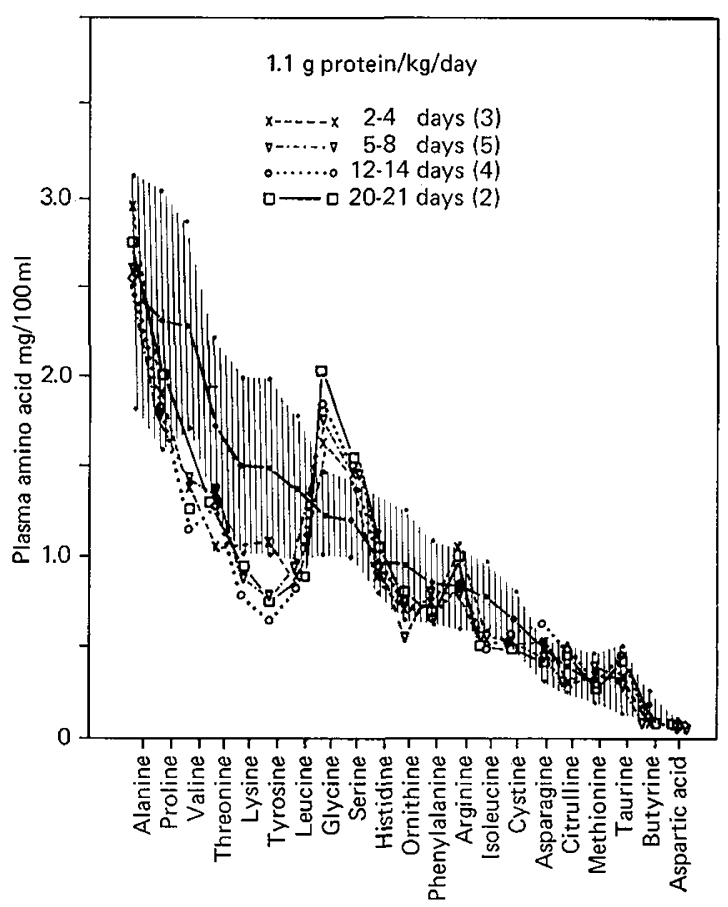




\begin{tabular}{|c|c|c|c|c|c|c|c|c|c|c|c|c|c|c|c|c|c|c|c|c|c|c|c|c|}
\hline 命 & 品 & 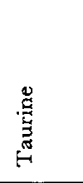 & 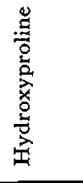 & 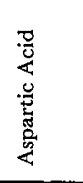 & 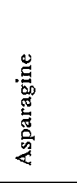 & 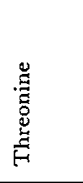 & 营 & 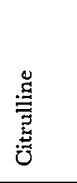 & 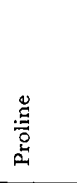 & 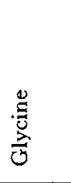 & 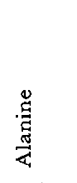 & 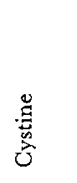 & 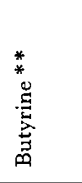 & 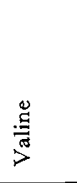 & 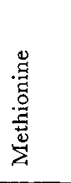 & 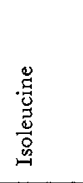 & 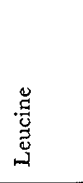 & 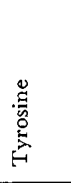 & 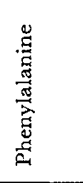 & 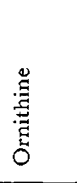 & 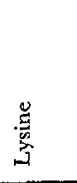 & 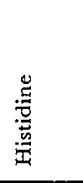 & 莺 & 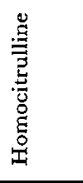 \\
\hline $\mathrm{Ma}$ & 1 month & 0.44 & $\operatorname{tr}$ & 0.10 & 0.47 & 1.20 & 1.23 & 0.30 & 3.20 & 1.56 & 2.98 & 0.45 & 0.13 & 2.11 & 0.33 & 0.83 & 1.49 & 1.42 & 0.68 & 1.49 & 2.29 & 1.00 & 0.84 & $\operatorname{tr}$ \\
\hline Ow & 1 month & 0.43 & 0 & 0.09 & - & - & - & 0.35 & 1.40 & 0.93 & 1.55 & 0.65 & 0.32 & 2.13 & 0.26 & 0.57 & 1.07 & 1.21 & 0.58 & - & 1.59 & 0.61 & 0.83 & 0 \\
\hline Es & 1 month & 0.33 & 0.44 & 0.12 & 0.45 & 2.17 & 1.04 & 0.40 & 2.42 & 1.42 & 2.44 & 0.63 & 0.17 & 1.98 & 0.09 & 0.51 & 1.19 & 0.93 & 0.54 & - & 0.78 & 0.75 & 0.84 & 0 \\
\hline $\mathrm{Ed}$ & 1 month & 0.25 & 0.25 & 0.06 & 0.46 & 0.97 & 0.96 & 0.48 & 1.82 & 0.93 & 1.50 & 0.65 & 0.12 & 1.45 & 0.19 & 0.66 & 1.17 & 1.53 & 0.72 & 0.83 & 1.92 & 1.03 & 1.10 & 0.06 \\
\hline $\mathrm{Be}$ & 1 month & 0.51 & 0.24 & 0.06 & 0.50 & 1.36 & 1.21 & 0.44 & 1.98 & 1.20 & 2.11 & 0.70 & 0.19 & 2.04 & 0.22 & 0.68 & 1.27 & 0.93 & 0.79 & 0.54 & 1.61 & 0.95 & 1.18 & 0 \\
\hline Jo & 5 weeks & 0.33 & tr & 0.10 & 0.74 & 1.65 & 1.19 & 0.40 & 2.38 & 1.06 & 2.18 & 0.71 & 0.30 & 2.28 & 0.24 & 0.88 & 1.64 & 1.30 & 0.82 & 0.53 & 1.37 & 1.04 & 0.80 & 0.34 \\
\hline $\mathrm{Ec}$ & 5 weeks & - & 0.26 & 0.08 & 0.52 & 1.39 & 1.26 & 0.45 & 1.95 & 1.32 & 2.85 & 0.75 & 0.12 & 1.62 & 0.21 & 0.57 & 1.03 & 1.34 & 0.73 & 0.94 & 1.83 & 1.11 & 1.09 & 0.07 \\
\hline Ko & 5 weeks & 0.23 & 0.32 & $\operatorname{tr}$ & 0.49 & 1.32 & 1.18 & 0.44 & 1.72 & 1.22 & 1.89 & 0.80 & 0.18 & 1.65 & 0.27 & 0.51 & 0.98 & 0.91 & 0.51 & 0.88 & 1.60 & 0.97 & 0.92 & 0.12 \\
\hline $\mathrm{Ol}$ & 5 weeks & 0.29 & 0 & $\operatorname{tr}$ & 0.43 & 1.73 & 1.55 & 0.55 & 2.83 & 1.19 & 2.03 & 0.78 & 0.11 & 2.42 & 0.33 & 0.79 & 1.52 & 2.06 & 0.66 & 1.17 & 1.19 & 0.88 & 1.42 & 0.08 \\
\hline $\mathrm{Ev}$ & 5 weeks & 0.59 & 0 & - & 0.34 & 0.92 & 0.61 & 0.35 & 1.50 & 1.42 & 2.23 & 0.17 & 0.07 & 1.40 & 0.23 & 0.55 & 0.96 & 0.93 & 0.55 & 0.73 & 0.74 & 0.90 & 0.65 & 0 \\
\hline $\mathrm{Ni}$ & 5 weeks & 0.19 & 0 & $\operatorname{tr}$ & 0.42 & 1.56 & 1.10 & 0.21 & 3.40 & 0.89 & 2.61 & 0.47 & 0.28 & 3.24 & 0.36 & 1.24 & 2.17 & 2.18 & 1.28 & 0.98 & 2.15 & 0.94 & 0.84 & 0 \\
\hline Ec & 6 weeks & 0.16 & 0.40 & 0.07 & 0.33 & 3.13 & 1.65 & 0.14 & 2.58 & 1.62 & 2.10 & 0.54 & 0.11 & 2.12 & 0.45 & 0.62 & 1.28 & 1.69 & 1.28 & - & 1.86 & 1.20 & 1.21 & 0.15 \\
\hline $\mathrm{Br}$ & 6 weeks & 0.17 & $\operatorname{tr}$ & - & 0.48 & 1.72 & 1.14 & 0.59 & 2.53 & 0.99 & 1.66 & 0.71 & 0.24 & 2.55 & 0.36 & 0.76 & 1.48 & 1.53 & 0.72 & 0.85 & 1.52 & 1.02 & 0.81 & 0.37 \\
\hline $\mathrm{Ri}$ & 7 weeks & 0.36 & 0 & 0.15 & 0.47 & 2.05 & 1.02 & 0.12 & 1.61 & 0.99 & 2.55 & - & 0.31 & 2.40 & 0.40 & 0.88 & 1.60 & 1.46 & 0.93 & 0.66 & 1.56 & 1.09 & - & 0 \\
\hline $\mathrm{Sa}$ & 7 weeks & 0.38 & $\operatorname{tr}$ & tr & 0.35 & 2.19 & 1.72 & 0.34 & 3.45 & 0.95 & 3.54 & 0.73 & 0.23 & 2.83 & 0.39 & 0.78 & 1.37 & 1.49 & 0.86 & 0.95 & 1.50 & 1.21 & - & 0.35 \\
\hline $\mathrm{Gi}$ & 7 weeks & 0.22 & $\operatorname{tr}$ & $\operatorname{tr}$ & 0.62 & 1.47 & 1.62 & 0.43 & 1.52 & 1.18 & 2.81 & 0.65 & 0.15 & 1.83 & 0.39 & 0.61 & 1.05 & 1.14 & 0.65 & 1.0 & 1.31 & 0.90 & 1.11 & 0 \\
\hline No & 8 weeks & - & 0 & 0.14 & 0.42 & 2.81 & 1.19 & 0.32 & 1.97 & 1.54 & 4.15 & - & 0.10 & 1.99 & 0.44 & 0.73 & 0.93 & 0.76 & 0.93 & 0.69 & 0.95 & 1.01 & - & 0 \\
\hline BI & 2 months & 1.11 & 0 & 0.05 & - & 1.72 & 1.20 & 0.37 & 2.64 & 1.06 & 1.80 & 1.15 & 0.27 & 2.92 & 0.29 & 0.91 & 1.67 & 1.51 & 0.81 & 0.72 & 1.62 & 0.97 & 1.17 & 0 \\
\hline $\mathrm{Ma}$ & 2 months & 0.22 & $\operatorname{tr}$ & 0.16 & 0.55 & 1.20 & 1.31 & 0.42 & 4.85 & 0.72 & 2.90 & 0.26 & 0.26 & 3.13 & 0.36 & 1.14 & 1.96 & 1.95 & 1.05 & 1.02 & 2.52 & 1.23 & 0.87 & 0.33 \\
\hline $\mathrm{Oq}$ & 2 months & 0.11 & 0 & 0.03 & 0.28 & 1.74 & 1.20 & 0.30 & 1.74 & 1.37 & 3.15 & 0.66 & 0.12 & 1.55 & 0.20 & 0.49 & 0.89 & 1.15 & 0.55 & 0.51 & 0.97 & 0.76 & 0.47 & 0 \\
\hline St & 2 months & 0.40 & 0 & $\operatorname{tr}$ & 0.40 & 2.19 & 1.17 & 0.46 & 2.91 & 0.92 & 2.70 & 0.52 & 0.25 & 2.52 & 0.38 & 0.78 & 1.51 & 1.36 & 0.88 & 1.07 & 1.64 & 1.21 & 0.88 & 0.26 \\
\hline Mo & 2 months & 0.29 & 0 & $\operatorname{tr}$ & 0.48 & 2.28 & 1.19 & 0.25 & 1.95 & 1.23 & 2.80 & 0.50 & 0.11 & 1.90 & 0.46 & 0.76 & 1.28 & 2.06 & 0.94 & 0.90 & 1.50 & 1.02 & 0.72 & 0 \\
\hline $\mathrm{La}$ & $21 / 2$ months & 0.36 & 0 & 0.04 & 0.43 & - & 1.20 & 0.32 & 2.31 & 1.51 & 2.45 & 0.65 & 0.19 & 2.51 & 0.30 & 0.78 & 1.42 & 1.15 & 0.78 & 0.76 & 1.15 & 1.22 & 0.73 & 0.16 \\
\hline Co & 3 months & 0.13 & 0 & 0.05 & 0.34 & 1.79 & 1.15 & 0.29 & 2.38 & 0.96 & 2.65 & 0.70 & 0.23 & 2.72 & 0.29 & 0.85 & 1.61 & 1.86 & 1.24 & 1.93 & 1.83 & 0.92 & - & 0 \\
\hline Le & 3 months & 0.66 & 0 & 0.06 & 0.50 & 2.34 & 1.12 & 0.21 & 2.99 & 1.05 & 2.47 & 0.50 & 0.11 & 2.98 & 0.26 & 1.07 & 1.87 & 1.50 & 1.23 & 1.26 & 1.67 & 0.78 & 1.07 & 0 \\
\hline Ew & 3 months & 0.29 & $\operatorname{tr}$ & 0.08 & 0.59 & 2.48 & 1.96 & 0.45 & 2.53 & 1.45 & 3.27 & 0.61 & 0.17 & 1.84 & 0.27 & 0.81 & 1.07 & 1.39 & 0.54 & 1.13 & 1.53 & 1.36 & 1.02 & 0.08 \\
\hline $\operatorname{Re}$ & 3 months & 0.13 & 0 & 0.05 & 0.37 & 1.88 & 1.23 & 0.57 & 2.60 & 1.82 & 2.03 & 0.96 & 0.11 & 1.89 & 0.32 & 0.71 & 1.15 & 1.80 & 1.27 & 0.81 & 1.33 & 0.89 & 0.65 & 0 \\
\hline $\mathrm{Fl}$ & 3 months & 0.16 & 0 & 0.07 & 0.37 & 1.44 & 1.22 & 0.19 & 1.95 & 1.28 & 2.32 & 0.76 & 0.11 & 2.17 & 0.19 & 0.69 & 1.15 & 1.13 & 0.92 & 0.75 & 1.29 & 0.83 & 0.83 & 0 \\
\hline Th & 3 months & 0.45 & 0.32 & 0.08 & 0.49 & 1.76 & 1.38 & 0.56 & 1.42 & 1.08 & 1.84 & 1.03 & 0.27 & 1.91 & 0.32 & 0.74 & 1.28 & 1.33 & 0.74 & - & 2.12 & 0.64 & 0.83 & $\operatorname{tr}$ \\
\hline \multirow{2}{*}{\multicolumn{2}{|c|}{$\begin{array}{l}\text { Average } \\
\text { Standard deviation } \pm\end{array}$}} & 0.31 & $*$ & 0.05 & 0.41 & 1.72 & 1.20 & 0.37 & 2.31 & 1.23 & 2.45 & 0.65 & 0.17 & 2.27 & 0.32 & 0.78 & 1.37 & 1.49 & 0.86 & 0.95 & 1.50 & 0.97 & 0.83 & * \\
\hline & & 0.18 & & 0.03 & 0.10 & 0.48 & 0.20 & 0.13 & 0.71 & 0.22 & 0.63 & 0.16 & 0.09 & 0.57 & 0.13 & 0.19 & 0.40 & 0.48 & 0.23 & 0.30 & 0.48 & 0.16 & 0.23 & \\
\hline \multicolumn{7}{|c|}{ - Result not possible because of technical problem } & \multicolumn{10}{|c|}{ * Not averaged because of large number of 0 values } & \multicolumn{6}{|c|}{$* *=\alpha$ amino $\mathrm{n}$ butyric acid } & \multicolumn{2}{|c|}{$\operatorname{tr}=\operatorname{trace}$} \\
\hline
\end{tabular}


Table III. Plasma aminogram of infants fed $1.1 \mathrm{~g}$ protein $/ \mathrm{kg} /$ day (values recorded in $\mathrm{mg} / 100 \mathrm{ml}$ )

\begin{tabular}{|c|c|c|c|c|c|c|c|c|c|c|c|c|c|c|c|c|c|c|c|c|c|c|}
\hline 令 & 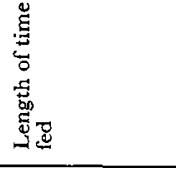 & 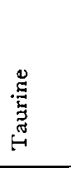 & 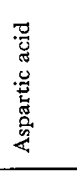 & 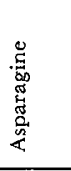 & 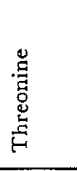 & 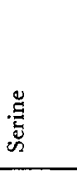 & 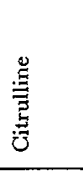 & 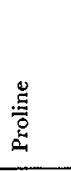 & 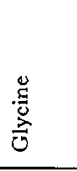 & 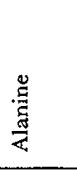 & 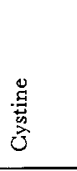 & 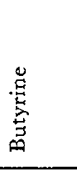 & $\begin{array}{l}\stackrel{\mathscr{\Xi}}{\tilde{n}} \\
\stackrel{2}{>}\end{array}$ & 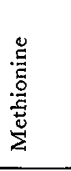 & 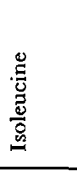 & 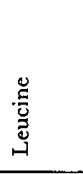 & 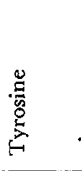 & 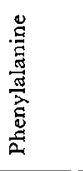 & 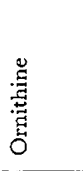 & $\begin{array}{l}\text { 量 } \\
\text { 空 }\end{array}$ & 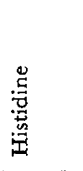 & 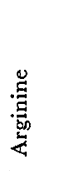 \\
\hline $\mathrm{Be}$ & 2 days & 0.32 & 0.01 & 0.63 & 1.24 & 1.13 & 0.25 & 1.80 & 1.71 & 2.14 & 0.54 & 0.04 & 1.35 & 0.21 & 0.51 & 0.94 & 1.42 & 0.80 & 0.94 & 0.98 & 0.81 & 1.34 \\
\hline $\mathrm{Ec}$ & 2 days & 0.30 & 0.04 & 0.38 & 0.91 & 1.65 & 0.24 & 1.81 & 1.71 & 2.44 & 0.61 & 0.07 & 1.32 & 0.31 & 0.45 & 0.78 & 0.98 & 0.78 & 0.61 & 0.97 & 1.08 & 0.85 \\
\hline Jo & 4 days & 0.35 & 0.05 & 0.58 & 1.00 & 1.58 & 0.33 & 2.00 & 1.43 & 4.18 & 0.46 & 0.06 & 1.49 & 0.41 & 0.58 & 0.99 & 0.81 & 0.61 & 0.56 & 1.12 & 0.83 & 0.89 \\
\hline Average & $2-4$ days & 0.32 & 0.03 & 0.53 & 1.05 & 1.45 & 0.27 & 1.87 & 1.62 & 2.92 & 0.50 & 0.06 & 1.37 & 0.31 & 0.51 & 0.87 & 1.07 & 0.73 & 0.70 & 1.02 & 0.87 & 1.03 \\
\hline Ec & 5 days & 0.12 & 0.04 & 0.28 & 1.30 & 1.18 & 0.14 & 1.56 & 1.42 & 1.45 & 0.40 & 0.03 & 1.10 & 0.27 & 0.41 & 0.74 & 0.73 & 0.85 & 0.51 & 0.56 & 0.74 & 0.76 \\
\hline $\mathrm{Al}$ & 6 days & 0.27 & 0.13 & 0.49 & 1.25 & 1.59 & 0.26 & 2.06 & 1.98 & 3.37 & 0.60 & 0.05 & 1.44 & 0.26 & 0.63 & 1.02 & 0.84 & 0.72 & 0.57 & 1.05 & 1.01 & 0.82 \\
\hline $\mathrm{Be}$ & 1 week & 0.50 & 0.13 & 0.51 & 1.45 & 1.53 & 0.20 & 1.74 & 1.95 & 2.02 & 0.50 & 0.04 & 1.21 & 0.33 & 0.45 & 0.84 & 0.81 & 0.74 & 0.49 & 0.93 & 0.95 & 0.84 \\
\hline $\mathrm{Ed}$ & 1 week & 0.50 & 0.07 & 0.53 & 1.39 & 1.58 & 0.34 & 1.56 & 2.20 & 2.75 & 0.52 & 0.06 & 1.22 & 0.33 & 0.44 & 0.88 & 0.70 & 0.75 & 0.64 & 0.80 & 1.03 & 0.89 \\
\hline Jo & 8 days & 0.27 & 0.07 & 0.35 & 1.55 & 1.40 & 0.31 & 2.00 & 1.24 & 3.38 & 0.54 & 0.10 & 1.60 & 0.35 & 0.57 & 1.13 & 0.69 & 0.61 & 0.59 & 1.08 & 0.80 & 0.72 \\
\hline Average & 5-8 days & 0.31 & 0.09 & 0.43 & 1.35 & 1.44 & 0.25 & 1.78 & 1.76 & 2.57 & 0.51 & 0.06 & 1.31 & 0.31 & 0.50 & 0.91 & 0.76 & 0.73 & 0.54 & 0.88 & 0.88 & 0.78 \\
\hline $\mathrm{Ec}$ & 12 days & 0.35 & 0.03 & 0.45 & 1.39 & 1.37 & 0.30 & 1.67 & 1.61 & 2.50 & 0.43 & 0.04 & 0.88 & 0.23 & 0.34 & 0.64 & 0.47 & 0.55 & 0.72 & 0.53 & 0.76 & 0.65 \\
\hline $\mathrm{Al}$ & 13 days & 0.54 & 0.10 & 0.50 & 1.08 & 1.55 & 0.53 & 2.31 & 2.34 & 3.66 & 0.60 & 0.04 & 1.45 & 0.28 & 0.54 & 0.92 & 0.78 & 0.68 & 0.77 & 0.87 & 1.38 & 0.83 \\
\hline $\mathrm{Be}$ & 14 days & 0.44 & 0.05 & 0.54 & 1.53 & 1.57 & 0.49 & 1.78 & 1.87 & 2.04 & 0.67 & 0.02 & 1.22 & 0.25 & 0.50 & 0.94 & 0.81 & 0.80 & 0.67 & 0.95 & 0.81 & 1.03 \\
\hline Ed & 14 days & 0.42 & 0.06 & 0.45 & 1.03 & 1.49 & 0.55 & 1.55 & 1.56 & 2.00 & 0.54 & 0.05 & 1.03 & 0.22 & 0.49 & 0.72 & 0.49 & 0.53 & 0.81 & 0.74 & 0.89 & 0.81 \\
\hline Average & 12-14 days & 0.44 & 0.06 & 0.48 & 1.26 & 1.49 & 0.47 & 1.80 & 1.82 & 2.55 & 0.53 & 0.04 & 1.14 & 0.25 & 0.48 & 0.81 & 0.64 & 0.64 & 0.74 & 0.78 & 0.96 & 0.83 \\
\hline & 20 days & 0.46 & 0.05 & 0.56 & 1.30 & 1.53 & $0.5 \mathrm{l}$ & 2.11 & 2.10 & 3.27 & 0.47 & 0.06 & 1.34 & 0.29 & 0.56 & 0.94 & 0.78 & 0.67 & 0.75 & 0.98 & 1.20 & 1.03 \\
\hline & 21 days & 0.40 & 0.07 & 0.44 & 1.40 & 1.47 & 0.31 & 1.87 & 1.90 & 2.33 & 0.52 & 0.03 & 1.16 & 0.23 & 0.48 & 0.84 & 0.72 & 0.73 & 0.75 & 0.91 & 0.87 & 1.00 \\
\hline Average & $20-21$ days & 0.43 & 0.06 & 0.50 & 1.35 & 1.50 & 0.41 & 1.99 & 2.00 & 2.72 & 0.49 & 0.05 & 1.25 & 0.26 & 0.52 & 0.89 & 0.75 & 0.70 & 0.75 & 0.94 & 1.03 & 1.01 \\
\hline
\end{tabular}




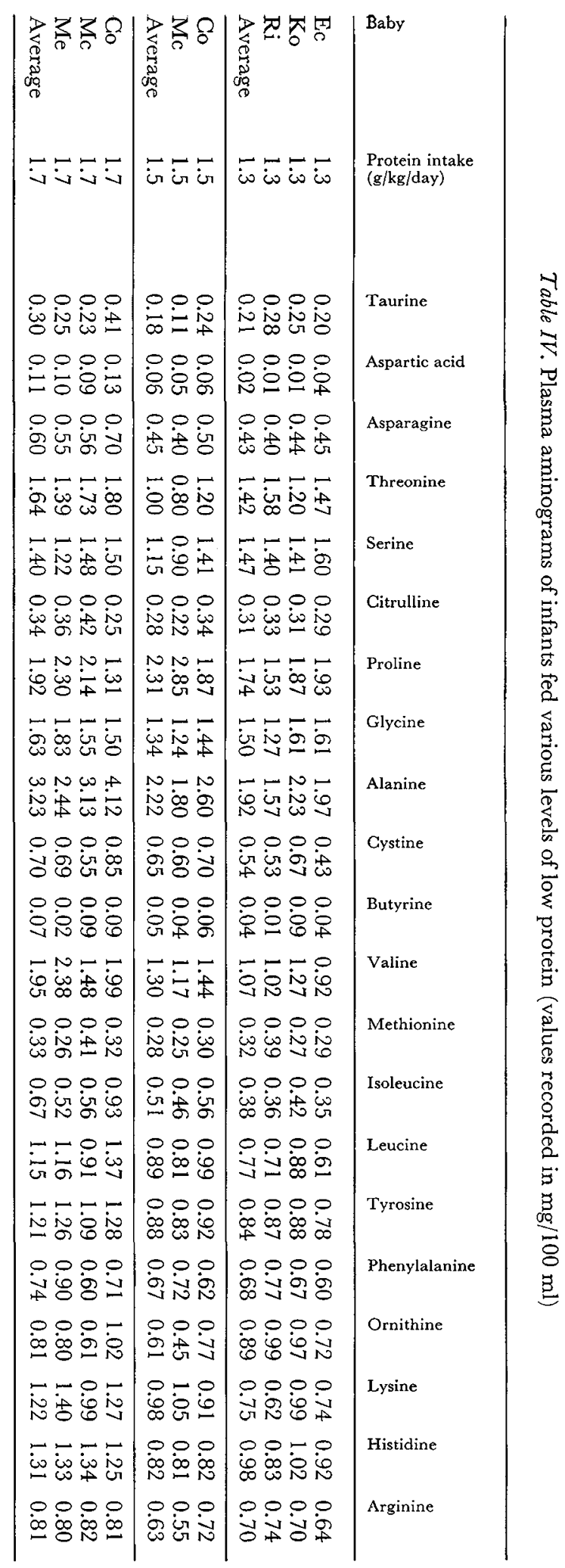

QVYTVSNYHC 'NVWLIOY 'NOLYON 'LTOH 'NVWYGAXNS 


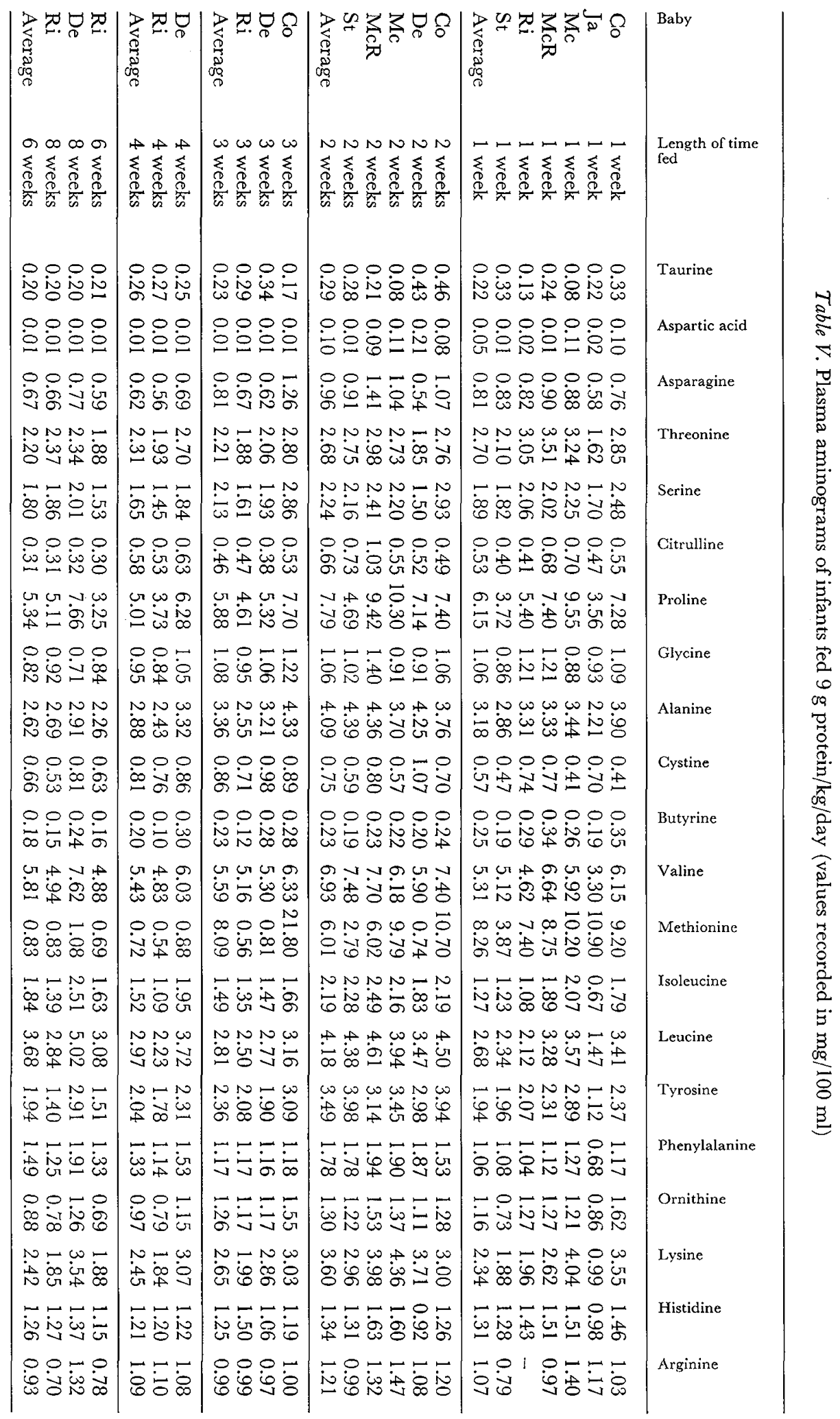

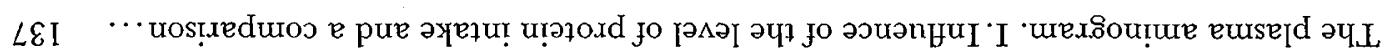




\begin{tabular}{|c|c|c|c|c|c|c|c|c|c|c|c|c|c|c|c|c|c|c|c|c|c|c|}
\hline 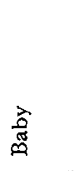 & 总 & 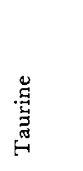 & 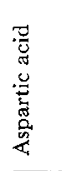 & 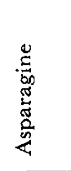 & 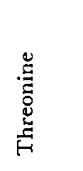 & 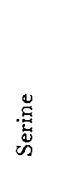 & 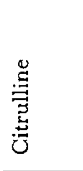 & 苛 & 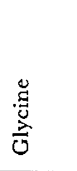 & 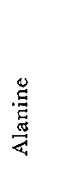 & 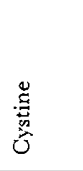 & 莺 & 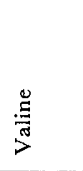 & 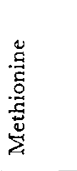 & 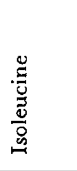 & 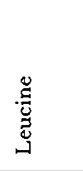 & 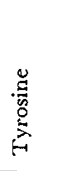 & 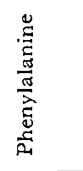 & & 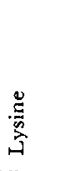 & 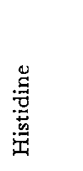 & 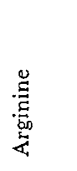 \\
\hline Go & month & 0.43 & 0.16 & 0.18 & 1.52 & 1.53 & 0.28 & 1.46 & 1.71 & 3.08 & - & 0.12 & 1.45 & 0.25 & 0.68 & 1.07 & 1.00 & 0.82 & 0.65 & 1.46 & 0.65 & 0.92 \\
\hline Es & nonth & .31 & .12 & 0.12 & 1.07 & 0.84 & 0.25 & 1.59 & 0.79 & 1.37 & - & 0.05 & 1.37 & 0.19 & 0.36 & 0.92 & 0.95 & 0.51 & - & 1.30 & 0.75 & 0.50 \\
\hline $\mathrm{Ga}$ & 1 month & 0.81 & 0.11 & 0.22 & 2.87 & 1.88 & 0.25 & 2.01 & 1.72 & 3.32 & 0.49 & 0.14 & 1.92 & 0.21 & 0.61 & 1.04 & 3.00 & 0.58 & 1.07 & 2.14 & 0.81 & 0.49 \\
\hline $\mathrm{Ki}$ & month & - & 0.14 & - & 1.37 & 1.64 & 0.14 & 1.68 & 1.28 & 2.96 & - & 0.17 & 1.13 & 0.13 & 0.48 & 1.12 & 0.94 & 0.54 & 0.89 & 0.94 & 0.66 & - \\
\hline Ve & 1 month & 0.68 & 0.09 & 0.22 & 1.91 & 1.31 & 0.34 & 1.85 & 1.82 & 2.78 & - & 0.08 & 1.71 & 0.36 & 0.46 & 1.12 & 1.55 & 0.99 & 1.38 & 2.26 & 0.89 & - \\
\hline $\mathrm{Di}$ & 1 month & 0.35 & 0.10 & 0.13 & 2.69 & 1.87 & 0.43 & 2.23 & 2.34 & 3.17 & - & 0.17 & 2.79 & 0.28 & 0.90 & 2.46 & 2.76 & 0.98 & - & 2.77 & 1.16 & - \\
\hline $\mathrm{BI}$ & & 48 & .09 & 0.19 & 2.95 & 1.63 & 0.11 & 2.08 & 1.80 & 2.78 & - & 14 & 1.64 & 0.26 & 0.62 & 0.98 & 1.45 & 0.79 & 0.68 & 1.76 & 0.84 & - \\
\hline $\mathrm{Ba}$ & onth & 14 & 0.07 & 0.18 & 1.58 & 1.35 & 0.30 & 1.20 & 1.56 & 1.67 & - & 0.14 & 1.61 & 0.28 & 0.57 & 1.12 & 1.95 & 0.78 & 0.73 & 1.59 & 0.99 & 1.0 \\
\hline Wa & onth & 34 & 0.01 & 0.26 & 2.36 & 1.93 & 0.30 & 2.36 & 1.90 & 2.77 & 0.80 & 0.13 & 2.01 & 0.22 & 0.34 & 1.06 & 1.55 & 0.52 & 0.93 & 1.52 & 1.19 & 0.71 \\
\hline Ro & 1 month & 0.26 & 0.03 & 0.22 & 2.19 & 1.80 & 0.33 & 2.40 & 2.84 & 3.35 & 0.89 & 0.22 & 1.80 & 0.56 & 0.53 & 1.07 & 1.51 & 1.01 & 1.13 & 1.93 & 1.03 & 0.93 \\
\hline $\mathrm{Al}$ & month & 0.28 & 0.07 & 0.31 & 2.02 & 1.27 & 0.35 & 1.83 & 1.08 & 1.81 & - & 0.12 & 1.69 & 0.19 & 0.46 & 0.99 & 1.13 & 0.62 & - & 1.38 & 0.66 & 0.79 \\
\hline $\mathrm{He}$ & & 0.13 & 0.07 & 0.30 & 2.32 & 1.67 & 0.25 & 1.15 & 1.80 & 2.11 & 0.26 & 0.09 & 1.41 & 0.18 & 0.31 & 0.85 & 1.38 & 0.57 & 1.02 & 1.88 & 0.89 & - \\
\hline $\mathrm{Be}$ & ionth & 0.51 & 0.01 & 0.29 & 1.58 & 1.23 & 0.30 & 2.00 & 1.67 & 2.80 & 0.62 & 0.13 & 1.91 & 0.30 & 0.54 & 1.10 & 1.03 & 0.81 & 0.89 & 1.77 & 1.18 & 1.03 \\
\hline $\mathrm{Da}$ & ionth & 0.45 & 0.01 & 0.22 & 1.69 & 1.01 & 0.31 & 2.46 & 1.54 & 2.32 & 0.75 & 0.11 & 1.34 & 0.25 & 0.52 & 1.02 & 1.17 & 0.70 & 0.86 & 1.47 & 1.03 & 0.90 \\
\hline $\mathrm{Gi}$ & 1 month & 0.71 & $\mathrm{tr}$ & 0.24 & 2.03 & 1.29 & 0.41 & 1.26 & 1.54 & 1.69 & 0.58 & 0.14 & 1.73 & 0.30 & 0.52 & 1.33 & 1.45 & 0.69 & 0.98 & 1.46 & 1.12 & 1.00 \\
\hline $\mathrm{Ge}$ & & & $\operatorname{tr}$ & 0.25 & 2.42 & 1.13 & 0.22 & 1.03 & & 1.79 & 0.44 & & 1.99 & 0.24 & 0.44 & 1.13 & 1.13 & 0.78 & 0.97 & 1.68 & 1.42 & 0.73 \\
\hline Lo & & .07 & $\operatorname{tr}$ & 0.14 & 1.28 & 0.96 & 0.19 & 1.43 & 1.17 & 2.24 & 0.55 & 0.08 & 1.56 & 0.21 & 0.37 & 1.02 & 1.36 & 0.65 & 1.02 & 1.29 & 0.88 & 0.47 \\
\hline DeB & onth & .26 & 0.01 & 0.43 & 2.48 & 1.41 & 0.37 & 2.64 & 2.19 & 3.98 & 0.84 & 0.14 & 1.81 & 0.33 & 0.53 & 1.13 & 1.26 & 0.73 & 1.12 & 1.59 & 1.17 & 1.16 \\
\hline $\mathrm{Ke}$ & onth & 19 & $\operatorname{tr}$ & 0.40 & 1.63 & 1.11 & 0.32 & 1.65 & 1.35 & 3.97 & 0.73 & 0.20 & 1.53 & 0.24 & 0.51 & 1.15 & 0.98 & 0.68 & 0.46 & 1.28 & 0.68 & 0.54 \\
\hline $\mathrm{Ma}$ & 1 month & 0.27 & 0.01 & 0.15 & 1.66 & 1.21 & 0.18 & 1.61 & 1.15 & 1.43 & 0.48 & 0.07 & 1.51 & 0.25 & 0.24 & 0.78 & 0.99 & 0.82 & 1.36 & 0.96 & 0.79 & - \\
\hline $\operatorname{Pr}$ & & 26 & .02 & 34 & - & 1.16 & 0.21 & 1.84 & 1.20 & 1.60 & 0.84 & & & 0.33 & 0.43 & 1. & & 0.75 & 1.80 & 1.63 & 1.26 & 0.67 \\
\hline $\mathrm{La}$ & & 45 & 0.13 & 6 & 1.6 & 1.61 & 0.36 & 1.9 & & 3.3 & & & & & & & & 0.93 & & 1.80 & 1.28 & 1.19 \\
\hline $\mathrm{Pe}$ & & .08 & 0.02 & 0.15 & 1.86 & 1.56 & 0.14 & 1.11 & 0.97 & 1.98 & 0.34 & 0.09 & 1.38 & 0.09 & 0.48 & 0.92 & 1.35 & 0.77 & 0.61 & 1.21 & 1.12 & 0.71 \\
\hline $\mathrm{Br}$ & & 0.18 & $\mathrm{tr}$ & 0.26 & 1.74 & 1.08 & 0.36 & 2.12 & 1.37 & 2.91 & 0.72 & 0.14 & 1.76 & 0.26 & 0.52 & 1.06 & 1.94 & 0.68 & 0.59 & 1.16 & 0.75 & 0.61 \\
\hline $\mathrm{Ma}$ & 1 month & 0.27 & 0.02 & 0.15 & 1.66 & 1.21 & 0.18 & 1.61 & 1.15 & 1.43 & 0.48 & 0.07 & 1.51 & 0.25 & 0.24 & 0.78 & 0.99 & 0.82 & 1.36 & 0.96 & 0.79 & - \\
\hline Mc & & .23 & 0.01 & 13 & 2.23 & 1.23 & 0.22 & 2.52 & 1.67 & 1.52 & 0.55 & 0.07 & 1.74 & 0.20 & 0.48 & 0.93 & 1.25 & 0.73 & 1.55 & 1.70 & 1.14 & 0.94 \\
\hline $\mathrm{Ru}$ & & & 0.01 & 0.12 & 3.03 & 0.98 & 0.17 & 1.75 & & 2.25 & 0.5 & 0.09 & 2.01 & 0. & 0.60 & & 1.80 & 0.66 & 0.59 & 1.30 & 0.88 & 0.85 \\
\hline Fr & & 0.42 & $\mathrm{tr}$ & 0.23 & 3.15 & 1.18 & 0.38 & 1.21 & 1.70 & 1.74 & 0.5 & 0.10 & 2.21 & 0.29 & 0.43 & 1.13 & 1.29 & 0.88 & 1.55 & 1.58 & 1.03 & - \\
\hline $\mathrm{Me}$ & & 0.31 & 0.01 & 0.34 & 1.47 & 1.33 & 0.63 & 1.46 & 1.48 & 2.08 & 0.69 & 0.20 & 1.70 & 0.34 & 0.40 & 1.07 & 1.01 & 0.64 & 1.44 & 1.51 & 0.97 & 1.10 \\
\hline $\mathrm{Li}$ & 1 month & 0.43 & $\operatorname{tr}$ & 0.28 & 1.90 & 1.96 & 0.37 & 1.61 & 2.54 & 2.59 & 0.92 & 0.15 & 2.04 & 0.34 & 0.43 & 1.12 & 2.60 & 0.85 & 1.00 & 1.79 & 0.98 & - \\
\hline
\end{tabular}




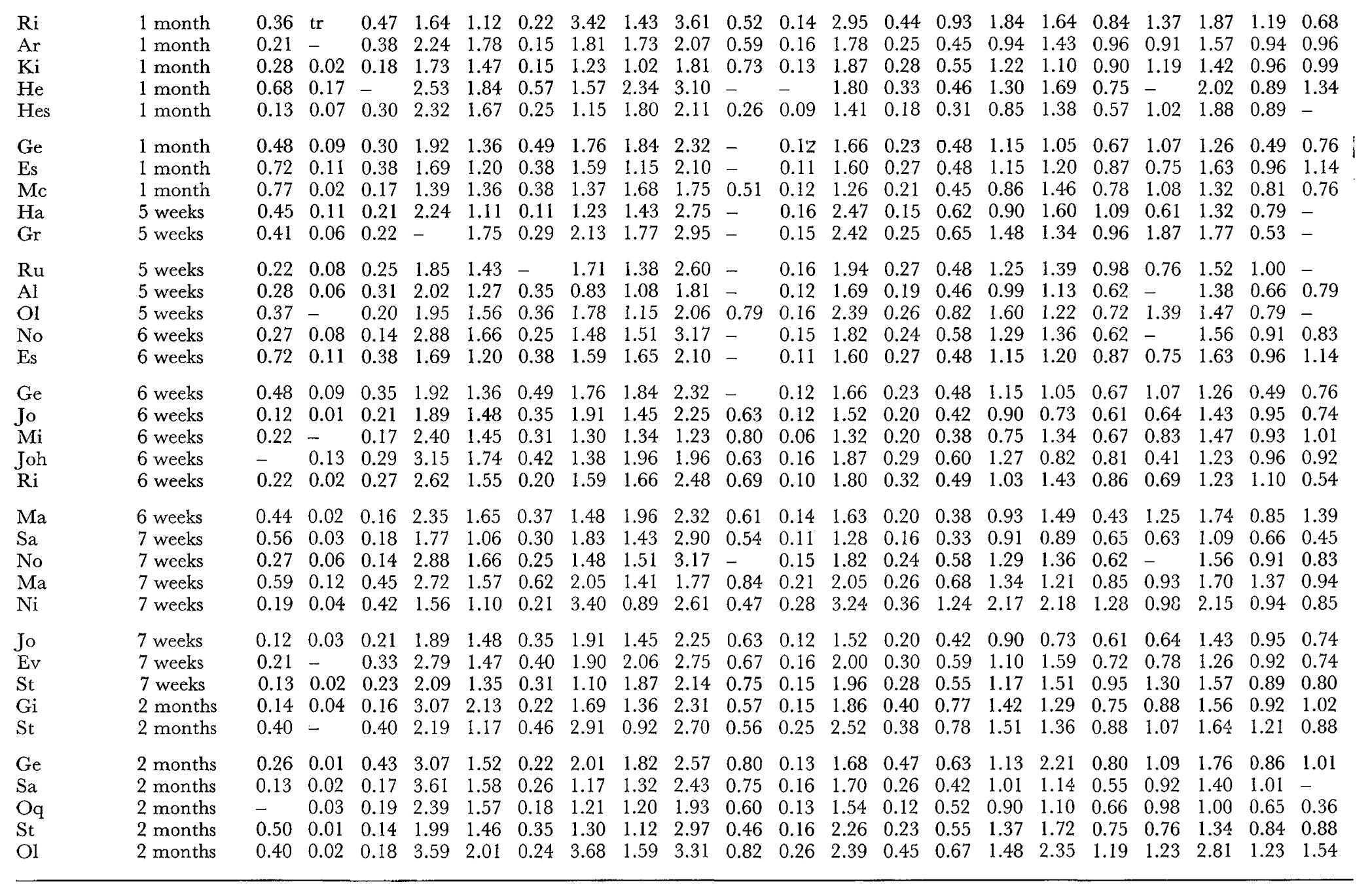

* Patients received diet from 1 to 4 weeks. 


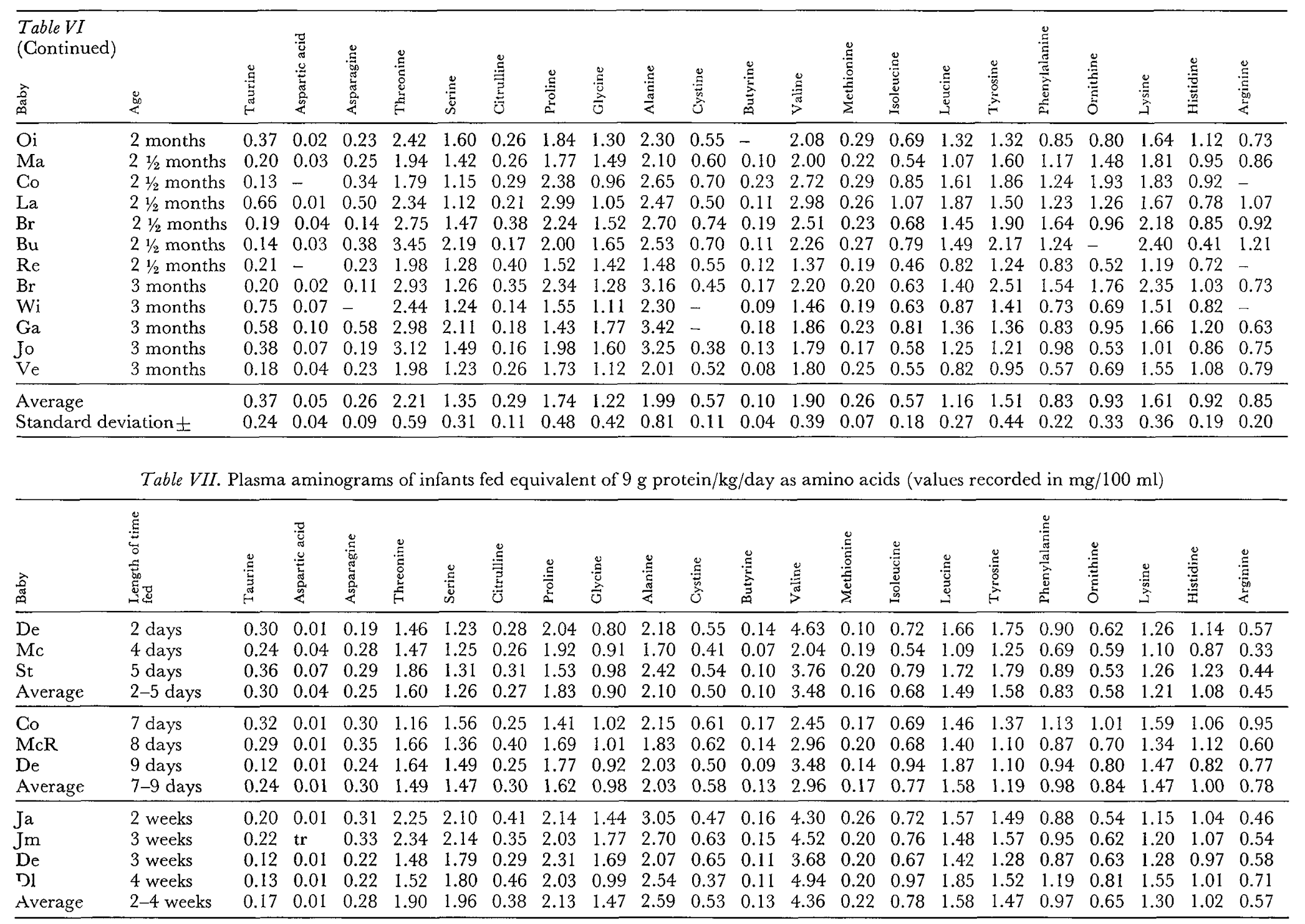


The plasma aminogram. I. Influence of the level of protein intake and a comparison...

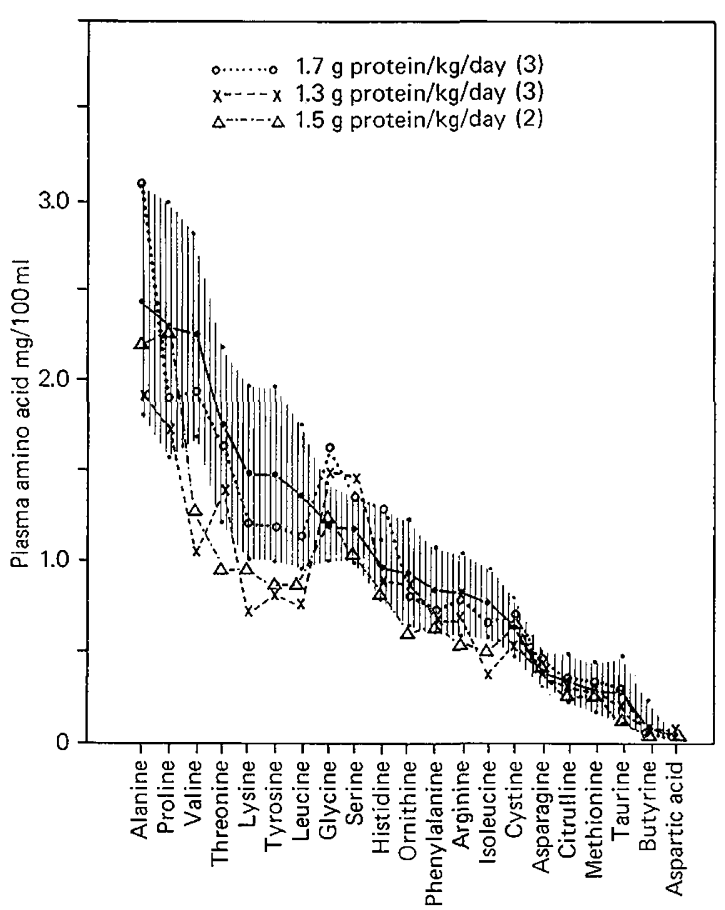

Fig. 3. The plasma aminogram after feeding 1.3, 1.5 and $1.7 \mathrm{~g}$ protein $/ \mathrm{kg} /$ day. The number of subjects are in the parentheses.

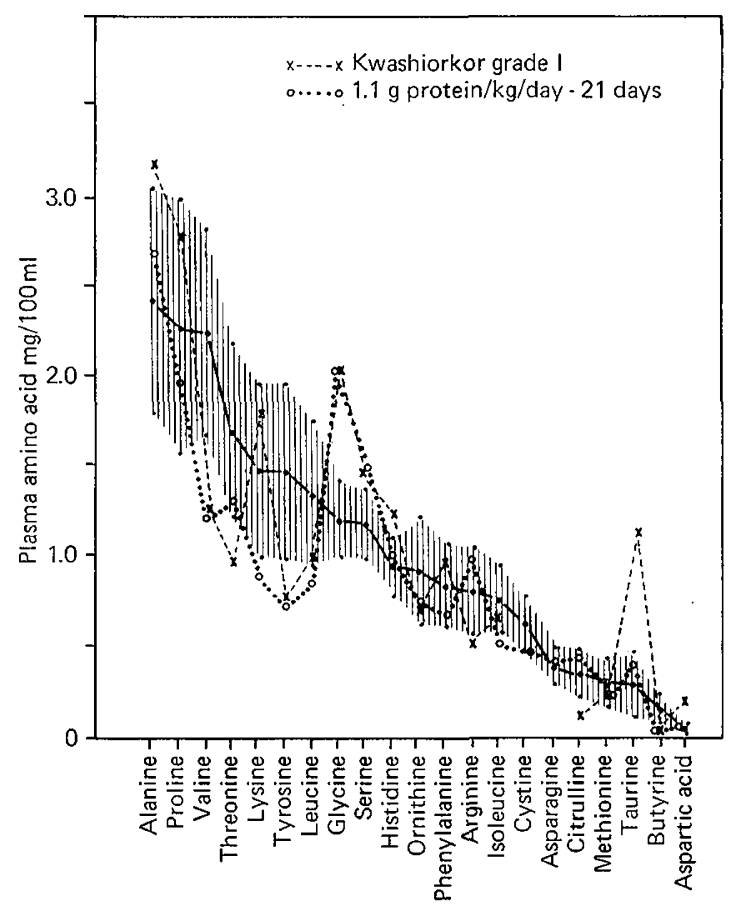

Fig.4. The plasma aminogram after feeding $1.1 \mathrm{~g}$ protein/day for 21 days compared to the plasma aminogram of grade I Kwashiorkor. the depression in levels of the branched chain amino acids (leucine, isoleucine and valine) and of lysine and tyrosine. Glycine and serine levels were both elevated, with glycine showing the greater elevation. Less striking changes occurred in the concentrations of threonine, of phenylalanine, of ornithine, of butyrine ${ }^{3}$, of cystine and of proline, all of which decreased.

Figure 3 represents the results obtained with three other levels of low protein feeding: 1.3, 1.5, and 1.7 $\mathrm{g} / \mathrm{kg} /$ day; these data are contained in table IV. The aminograms obtained with the 1.3 and $1.5 \mathrm{~g} / \mathrm{kg} /$ day feedings were very similar to those obtained with the more extreme degree of protein reduction. The aminogram after feeding $1.7 \mathrm{~g} / \mathrm{kg} /$ day remained within the range of average \pm one standard deviation except for the elevation in the level of glycine.

The aminogram on these low protein diets bears a close resemblance to those observed by ourselves [5] and others $[2,16]$ in Kwashiorkor and is also similar to that observed in adults on low protein diets [15]. In figure 4, the aminogram of an infant after 21 days on $1.1 \mathrm{~g}$ protein $/ \mathrm{kg} /$ day is compared with what we have described in a patient with grade I of Kwashiorkor [5]. Strikingly similar in both are the depressed Ievels of the branched chain amino acids and of tyrosine as well as the elevated levels of glycine and serine. There is a tendency for the concentrations of threonine and butyrine to be low. The concentration of cystine is not sustained as well as that of methionine; however, some dissimilarities are seen. The depression of lysine was not seen in grade I Kwashiorkor though it occurred in the more marked Kwashiorkor patterns. Not noted in our low milk diet patterns were elevations of aspartic acid and taurine and depressions of citrulline and arginine which we had observed in Kwashiorkor.

The effects of a high intake of milk protein $(9 \mathrm{~g} / \mathrm{kg} /$ day) on the aminogram are shown in figure 5 and presented in table V. Some increase in the levels of the majority of amino acids can be seen. The sole exception is glycine, which tends to be low. Marked increases occur in the branched chain amino acids, valine being the most affected; there is also a large increase in the level of proline. The greatest elevations occur in the levels of methionine which also show the most marked individual variation, elevations ranged from two to thirty-five times normal average value. An apparent tendency of the level of methionine to return towards normal with prolonged feeding of the high protein diet is evident in the graph. However, the significance of this finding must be questioned since the subjects who were maintained the longest on this diet were those who originally did not have the very high levels of methionine.

\footnotetext{
${ }^{3} \alpha$ amino n-butyric acid.
} 


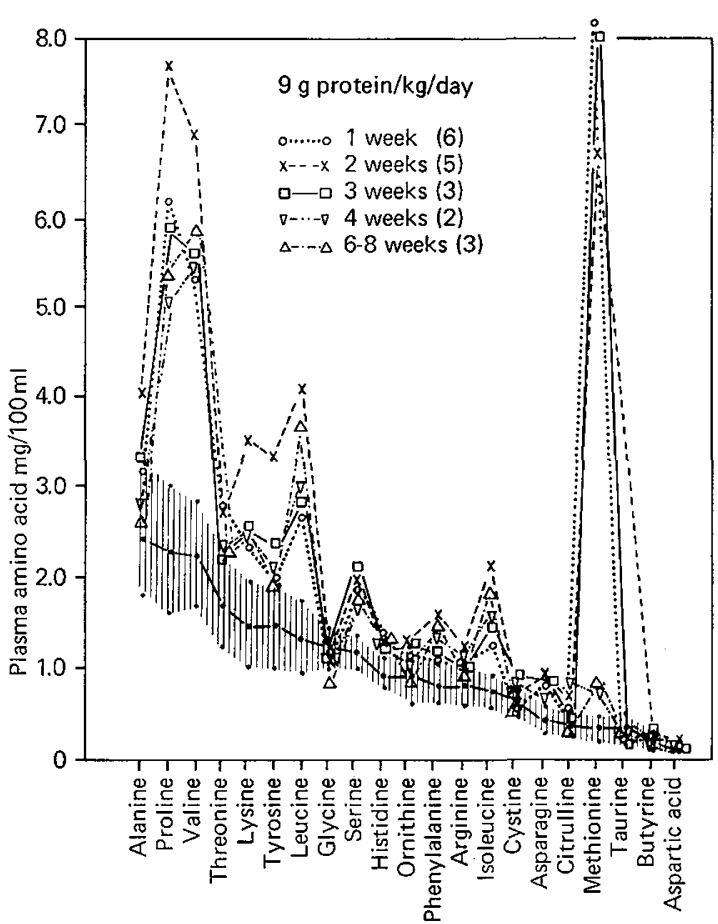

Fig. 5. The plasma aminogram after feeding $9 \mathrm{~g}$ milk protein $/ \mathrm{kg} /$ day for the lengths of time indicated on the figure. The number of subjects is indicated in the parentheses.

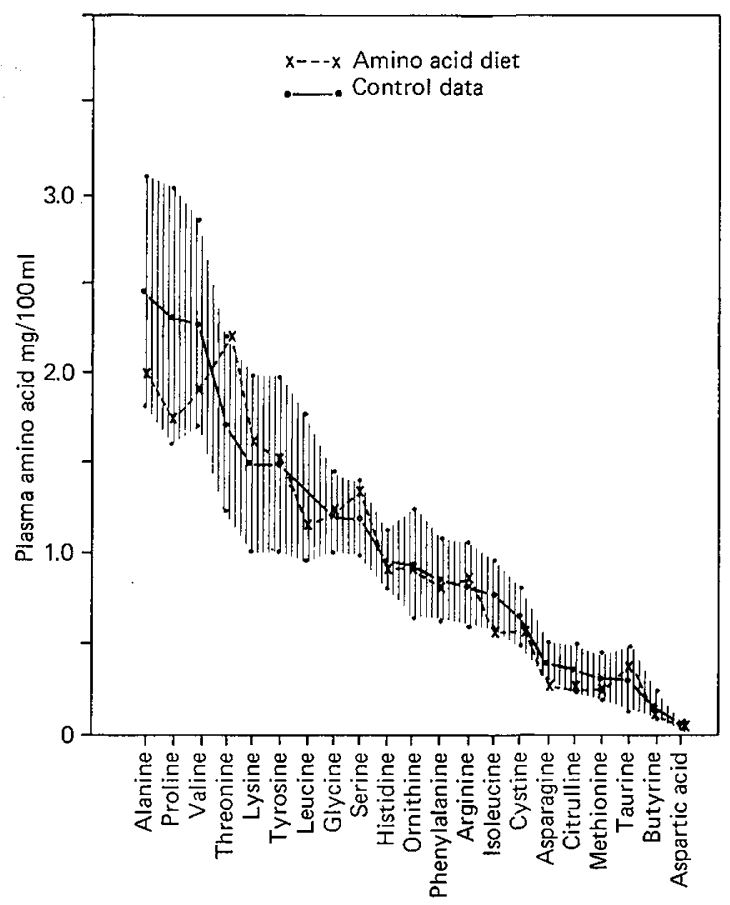

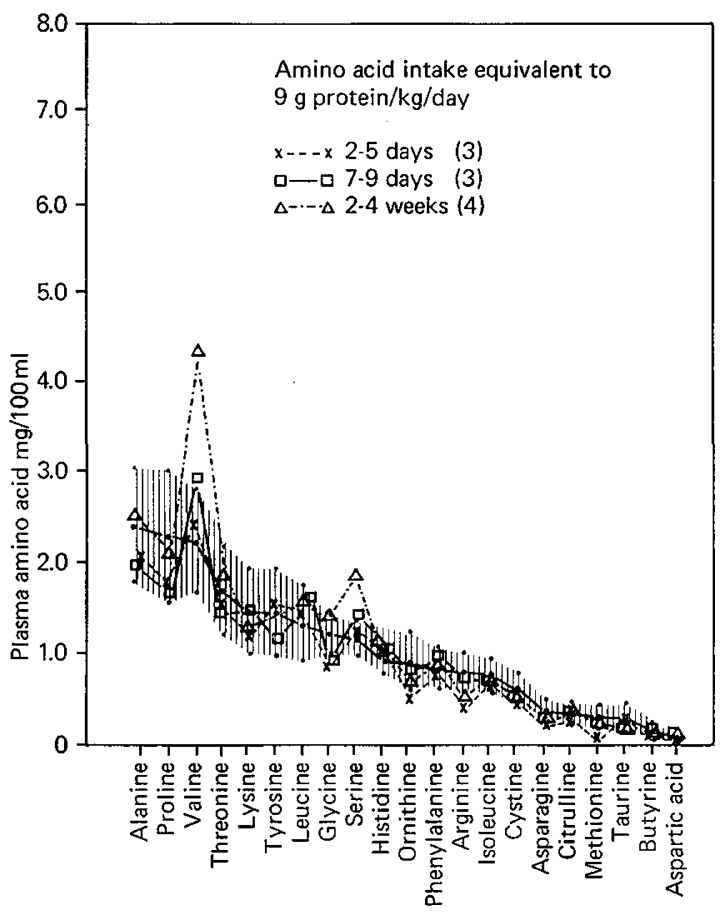

Fig.7. The plasma aminogram after feeding amino acid diets equivalent to $9 \mathrm{~g}$ protein $/ \mathrm{kg} /$ day for periods of time indicated on the figure. The number of subjects in each group are in the parentheses.

Comparisons of Whole Protein and Amino Acid Mixture Diets

In figure 6 is shown the average plasma aminogram from 77 infants fed a synthetic diet in which the nitrogenous moiety was supplied by a mixture of $18 \mathrm{~L}$ amino acids fed at a level equivalent to $3.5 \mathrm{~g}$ protein/ $\mathrm{kg} /$ day. The data are listed in table VI. This is plotted against the standard graph for the 29 infants of the whole protein control group fed at this same level. On the amino acid diets, lower average values are seen for the branched chain amino acids, for alanine and proline as well as for asparagine and citrulline; higher values are observed for threonine and serine.

In figure 7 are shown plasma aminograms from five subjects ingesting amino acid diets equivalent to $9 \mathrm{~g}$ protein $\mathrm{kg} /$ day. Table VII lists these values. These may be compared with those shown in figure 5 which shows the aminograms on $9 \mathrm{~g} / \mathrm{kg} /$ day of whole protein.

Fig.6. The average plasma aminogram of 77 infants fed a synthetic diet in which the nitrogenous moiety is a mixture of $18 \mathrm{~L}$-amino acids fed at a level equivalent to $3.5 \mathrm{~g}$ whole protein $/ \mathrm{kg} /$ day. These are plotted against the normal curve of figure 1 . 
The markedly elevated values seen in patients consuming high levels of whole protein are not seen in those receiving the high amino acid diets; only valine and serine show moderate elevations above the normal. When individual subjects were shifted from the high protein to the high amino acid diet, the pattern shifted within 24 hours to that shown in figure 7 . The significance of these changes will be discussed below.

\section{Discussion}

The response of the plasma aminogram to variations in protein intake is clear enough. The question whether the aminogram can be used to measure protein adequacy cannot be answered from the present data; we do not have any information that the presence of patterns characteristic of the low or the high intakes are in any way deleterious. Although the majority of children had some suppression in the rate of weight gain when given the lowest protein intake, two of the subjects continued to gain weight at their previous good rate, while the plasma aminogram showed the same deviations as in the other babies. On the other hand, the fact that the plasma aminogram following feeding with $1.7 \mathrm{~g} / \mathrm{kg}$ /day was within the normal range, except for the level of glycine, suggests that this intake might be close to the requirement figure. All three children maintained at this level continued to gain weight in a normal fashion. Since the requirements of all of the essential amino acids as previously determined in infants of this age group [6] were being met by this protein intake, the glycine elevation may possibly be a particularly early manifestation of 'unessential nitrogen' deficiency.

The interpretation of the differences in the response of the individual amino acids to the dietary shifts is of considerable interest. Plasma levels may conceivably be affected by several factors: by ease of assimilation, by the need for the amino acid, by the ease of degradation of unutilizable surpluses and by the ease of renal excretion. It is not possible at the present time to offer explanations for many of the observed changes, although some hypotheses can be suggested. The plasma levels of the branched chain amino acids appear to be particularly labile and to vary directly with intake. Their known rapidity of absorption from the gastrointestinal tract [1] and their relatively low hepatic metabolism [7] may explain this in part. More difficult to explain is the sharp decrease in lysine when subjects are on low protein diets and elevation of this amino acid when they are on a high protein diet; that a limiting value has been reached in the former case is not compatible with data on the infant's lysine requirement [11]. It is also difficult to explain the discrepancy between the more marked drop in the levels of lysine in plasma on the low milk diet as contrasted with its failure to fall strikingly in the mild cases of Kwashiorkor [5]. Do adaptive enzymes come into play here?

The great increase in plasma methionine after high protein may be attributed to a number of factors. Methionine is absorbed most efficiently from the gastrointestinal tract [1] and also is excreted in very small quantities in the urine. An additional factor in the extraordinary elevation in the level of this amino acid may be some failure in its catabolism; this is suggested by the lack of a concomitant increase in the cystine level. In unpublished studies [13], when infants were given a load of methionine which raised the levels to 16 to $23 \mathrm{mg} / 100 \mathrm{ml}$, there was very little increase in the cystine level.

The response of plasma glycine to dietary protein changes differed from that of the other amino acids; it rose with a reduced protein intake and fell with an increased protein intake. The simplest and most elementary explanation might be the readiness with which this amino acid enters many reactions in amino acid metabolism; its greater utilization with higher protein intakes might result in lower plasma levels at this time, and the reverse situation might occur with low protein intake. Regardless of the cause of the elevation, however, it might be a very important indicator of protein insufficiency. Further study of this amino acid in relation to protein intake seems indicated. The elevation of serine occurring at the same time as that of glycine is most likely the result of the readiness with which the reversible interconversion of glycine and serine takes place [10].

We do not have any explanation for the marked differences in the aminogram between high feeding of intact protein and amino acids. We have no reason to believe that amino acids are less well absorbed than intact protein; others $[3,4]$ have reported that intact protein and protein hydrolysates are equally well absorbed. Our own studies [13] have consistently shown a reduction in stool nitrogen when infants are shifted from milk to amino acid diets. The possibility does exist that amino acids given as such are more rapidly absorbed, and then more rapidly utilized or metabolized with the result that plasma levels have dropped to normal by the time fasting specimens are taken. Further studies, especially of postprandial blood samples, are contemplated to elucidate this problem.

\section{Summary}

The plasma aminogram of the infant responds promptly to alterations in protein intake. Low protein intakes are accompanied by a depression of the levels of a 
number of amino acids; the most striking changes are those for the branched chain amino acids, lysine and tyrosine; glycine and serine are exceptions and are elevated. High intakes of milk protein $(9 \mathrm{~g} / \mathrm{kg} /$ day $)$ result in elevation in levels of most of the amino acids, especially those of the branched chain amino acids, of proline and of methionine, while the level of glycine is depressed. In contrast, feeding the equivalent amount of nitrogen as a mixture of amino acids has little effect on the aminogram.

More study is needed before the amino acid levêls of the plasma can be used to ascertain the adequacy of protein intake. The paradoxical behavior of the level of glycine especially needs further investigation.

\section{References and Notes}

1. Adibi, S.A.; Gray, S.J. and Menden, E.: The kinetics of amino acid absorption and alteration of plasma composition of free amino acids after intestinal perfusion of amino acid mixtures. Amer.J. clin. Nutr. 20: 24-33 (1967).

2. Arroyave, G.; Wilson, D.; DE Funes, G. and BEHAR, M.: The free amino acids in blood plasma of children with Kwashiorkor and Marasmus. Amer.J.clin. Nutr. 11: 517-524 (1962).

3. Grane, G.W. and Newberger, A.: The digestion and absorption of protein by normal man. Biochem. J. 74: 313-323 (1960).

4. Gupta, J.D.; Dakroury, A.M. and Harper, A. E.: Observations on protein digestion in vivo. J. Nutr. 64: 447-456 (1958).

5. Holt, L. E., Jr.; SNyderman, S.E. ; Norton, P. M.; RoItman, E. and Finch, J.: The plasma aminogram in kwashiorkor. Lancet $i i$ : 1343-1348(1963).

6. Holt, L.E., Jr. and Snyderman, S. E.: The amino acid requirements of infants. J. amer. med. Ass. 175: 100-103 (1961).

7. MaMenamy, R.H.; Shoemaker, W. C.; Richman, J.E. and Elwyn, D.: Uptake and metabolism of amino acids by the dog liver perfused in situ. Amer. J. Physiol. 202: 407-414 (1962).
8. Moore, S. and Stein, W.H.: Chromatography of amino acids on sulfonated polystyrene resins. J. biol. Chem. 192: 663-681 (1951).

9. Piez, K. A. and Morris, L.: A modified procedure for the automatic analysis of amino acids. Anal. Biochem. 1: 187-201 (1960).

10. Siekevitz, P. and Greenberg, D.M.: Biological formation of serine from glycine. J. biol. Chem. 180: 845-856 (1949).

11. Snyderman, S.E.; Norton, P.M.; Fowler, D. I. and Horr, L. E., Jr.: The essential amino acid requirements of infants: Lysine. Amer.J. Dis. Child. 97: 175-185 (1959).

12. Snyderman, S. E. and Holr, L. E., Jr.: Unpublished data.

13. Snyderman, S. E. and Holr, L. E., Jr.: Unpublished observations.

14. Stern, W.H. and Moore, S. : The free amino acids of human blood plasma. J. biol. Chem. 211: 915926 (1954).

15. Swendeid, M.E.; Swendseid, M.D.; Tuttle, S. G.; Figueroa, W.S.; Mulcare, D.; Cllark, A.J. and MAssey, F.J.: Plasma amino acid levels of men fed diets differing in protein content. J. Nutr. 88: 239 (1966).

16. VIs, H.: Aspects et mécanismes des hyperaminoaciduries de l'enfance (Arscia, Bruxelles 1963).

17. The authors wish to express their gratitude to Mrs. Carrie Archer and the nursing staff of the Metabolic Unit for their devoted care of these infants.

18. Supported in part by NIH Grants HD 02561 and HD 00372.

19. Dr. Snyderman is the recipient of a Career Scientist Award of the Health Council of the City of New York under Contract 1-161.

20. Dr. Holt is the recipient of a Career Scientist Award of the Health Research Council of the City of New York under Contract 1-152.

21. Requests for reprints should be addressed to: Dr. Selma E. Snyderman, Professor of Pediatrics, New York University School of Medicine, 550 First Avenue, New York, N.Y. 10016 (USA). 